Narração como ato de ResistênCia em $O$ VALE DA PaIXÃo, de LÍDIA JORGE

Mariana JantSCH DE SOUZA*

ALFEU SPAREMBERGER**

\title{
RESUMO
}

Apresentamos uma leitura do romance $O$ Vale da Paixão, de Lídia Jorge, em que se evidencia o papel da narração como forma de resistência aos esquecimentos e silêncios familiares. Trata-se de uma narração que mobiliza memórias para consolidar uma identidade a partir da ressignificação do passado. A identidade é aqui abordada como um processo eminentemente discursivo atrelado à memória, uma vez que encontra no passado uma das principais fontes constituidoras. Nessa narrativa, o caminho para apaziguar os conflitos do passado é a escrita, a narração. Narrar um passado clandestino, do qual foi banida por meio do discurso familiar, forja-se como um ato de resistência.

Palavras-chave: narração, identidade, memória, O Vale da Paixão.

\section{ParÂMetros teóricos}

O romance de Lídia Jorge foi lido a partir das noções teóricas de memória e identidade. Esse olhar lançado sobre o romance encontra aporte na abordagem de Candau, Hall, Halbwachs, Sarlo. Entende-se a narração como ponto de articulação entre memória e identidade, uma vez que é por meio do discurso que o passado é mobilizado pela narradora para (re)constituir uma identidade proibida.

* Doutoranda em Letras, bolsista Capes, na Universidade Católica de Pelotas (UCPel), Pelotas, Rio Grande do Sul, Brasil. E-mail: marianajsouza@yahoo.com.br

** Professor na Universidade Federal de Pelotas (UFPel), Pelotas, Rio Grande do Sul, Brasil. E-mail: alfeusparemberger@terra.com.br 
Identidade é aqui considerada como construção discursiva e por isso é vista como um processo inacabado ou em constante aperfeiçoamento. Em razão disso, Hall entende que "a identidade surge não tanto da plenitude da identidade que já está dentro de nós como indivíduos, mas de uma falta de inteireza que é 'preenchida' a partir de nosso exterior, pelas formas através das quais nós imaginamos ser vistos por outros" (2006, p. 38-9).

Considerar que as identidades inserem-se num processo enfatiza sua condição discursiva: as identidades são construídas dentro do discurso. É no plano do discurso que as diferenças são estabelecidas e as posições sociais do sujeito são determinadas e assumidas.

Nesse sentido, as identidades são lidas como "pontos de apego temporário às posições-de-sujeito que as práticas discursivas constroem para nós. [...] as identidades são posições que o sujeito é obrigado a assumir, embora 'sabendo', sempre, que elas são representações" (HALL, 2011, p. 112). Uma representação convoca algo para ocupar o lugar de uma ausência, para preencher uma falta, um vazio deixado por outra coisa. A identidade, como representação, é construída ao longo de uma falta, "ao longo de uma divisão, a partir do lugar do Outro" por isso as identidades não podem "ser ajustadas - idênticas - aos processos de sujeito que são nelas investidos" (HALL, 2011, p. 112).?

Identidade significa, portanto, um ponto de encontro, o nó que une os diversos discursos e práticas culturais a que os sujeitos estão expostos e que os interpelam, convocando-os para que assumam seus lugares sociais (HALL, 2011, p. 112). Este nó, no entanto, pode ser feito de diversas formas e pode alterar-se a qualquer tempo. É este nó a identidade, a forma como o sujeito se identifica em certo momento e com relação a certos discursos.

Em relação à noção de memória que embasa a leitura, destaca-se que a memória é abordada como fonte de referentes identitários, como pilar a partir do qual se edificam as identidades, cujas vigas mestras são buscadas no passado e surgem sob a forma de lembranças.

Sendo a memória o instrumento capaz de trazer o passado para o presente, é inevitável atentar para a seletividade da memória, que não pode evocar todas as lembranças do indivíduo, mas opera uma seleção e faz emergir as imagens do passado que estão de acordo com as inten- 
ções atuais do sujeito, ou, como diz Candau, "a memória opera escolhas afetivas" (CANDAU, 2011, p. 69).

Neste horizonte, a memória forja-se como um gerenciador do passado, vez que não traz à mente do sujeito uma cópia fiel dos acontecimentos vivenciados, não encena exatamente o que foi vivido. Por esta faculdade humana, recupera-se o passado adaptando-o ao presente para fazê-lo atuar neste momento, pois "a alteração do passado é um atributo da memória que Pierre Nora definiu como 'a economia geral e gestão do passado no presente'. Essa gestão exige, por vezes, a criação deliberada de artifícios e artefatos memoriais" (CANDAU, 2011, p. 164). Esse trabalho de gestão também envolve a administração dos significados que se atribuem ao passado.

Para refletir sobre memória e identidade, considerando o discurso/ a narração como nó que une essas categorias e lhes dá forma, é importante perceber, conforme explica Sarlo (2007), que o relato da memória é por natureza lacunar, pois sua fonte é inexata, é uma ausência que se esforça por presentificar-se: "o aspecto fragmentário do discurso da memória, mais que uma qualidade a se afirmar como destino de toda obra de rememoração, é um reconhecimento exato de que a rememoração opera sobre algo que não está presente, para produzi-lo como presença discursiva" (2007, p. 99). Narrar, portanto, confere materialidade à memória e à identidade.

Em O Vale da Paixão, de Lídia Jorge (1998), a narração é construída diante da manta do soldado Walter, quando a narradora se defronta com a última - e única - herança do pai, sendo esse o último momento da filha com o pai Walter Glória Dias, representado pela manta.

A narradora, no instante em que recebe a relíquia do pai e diante dela, age como se fosse a hora da verdade, o momento para esclarecer o passado, desatar os nós da família e revelar o lugar de cada um no seio familiar. É o momento também de despir-se da culpa de ser filha e ao mesmo tempo sobrinha, de ter contribuído involuntariamente para o estado em que se encontra. É a hora de encontrar-se, de definir e assumir uma identidade: a de filha de Walter, já que esta é a última oportunidade para falar-lhe e a herança dirigida à filha cria o momento ideal - "para que Walter esta noite saiba": 
Mas se não tivesse sido eu, [...] Então eu era a responsável por aquela barca preta ter vindo a nossa porta para se afundar. Era culpada, responsável, duma responsabilidade mais funda que a culpa, porque nascida dum estado criado antes de mim mesma, uma condição herdada que me fizera à imagem e semelhança da própria culpa (JORGE, 1998, p. 136) ${ }^{1}$.

A manta forja a presença de Walter, a última presença, a qual é invocada constantemente, parecendo, por vezes, real. Assim, a figura de Walter trazida pela manta é o que provoca o ato memorial e induz às recordações narradas pela filha. A inscrição feita junto à relíquia: "deixo à minha sobrinha por única herança", é o primeiro passo em direção à identidade tão desejada. E essa narração revela-se como um ato de resistência, uma forma de conservar-se firme na posição de filha de Walter, posição identitária da qual foi banida pela família.

\section{A tessitura DisCURSIVA DE UMA IDENTIDADE: O ATO DE RESISTÊNCIA}

A filha de Maria Ema constrói o seu discurso narrativo após a morte do pai, ante ao objeto recebido como herança oficial: a manta do soldado Walter. Diante dessa herança ela quer, inicialmente, contar sua trajetória ao pai. Quer que ele, nessa noite, saiba como foi uma presença forte na vida da filha, ainda que a milhas de distância de Valmares. O discurso e a rememoração são dirigidos e dedicados a ele como uma última conversa.

Esse é o momento para extravasar tudo o que a mudez e a imobilidade de anos de silêncio familiar não permitiram que ela manifestasse na noite chuvosa de 1963, quando Walter Dias foi ao quarto da filha para falar-lhe. A rememoração e a narração têm como ponto de partida esse encontro, marcado pela clandestinidade dos laços entre Walter e a filha de Maria Ema e pela paralisia da moça diante da figura quase mítica do pai.

A filha reitera ao fim de cada flash mnemônico que gostaria que Walter soubesse de cada episódio rememorado e também daquilo que ela estimaria ter dito ao pai na noite de 1963, e assim revive o encontro: "E tudo isso ela teria conseguido explicar se tivesse tempo, [...] 
Queria ela dizer em voz alta para Walter Dias ouvir" (JORGE, 1998, p. 21, grifo nosso); "E só para o sossegar ela queria ter-se despregado da tábua da cama onde permanecia encostada, para se dirigir à gaveta da mesa onde guardava os desenhos e folheá-los, para ele mesmo poder ver com os seus próprios olhos o que lhe tinha dado sem ter prometido" (JORGE, 1998, p. 22-23, grifo nosso); "E era isso que ela queria dizer a Walter Dias, naquela noite condensada,[...] mas não tinha palavras, não tinha tempo, não podia" (JORGE, 1998, p. 33, grifo nosso).

Neste clima, a narradora reflete sobre seu passado e sobre todo o passado familiar. Seu discurso move-se pela necessidade de romper os obstáculos que separaram pai e filha ao longo de suas vidas. A rememoração, também guiada por essa intenção, faz emergir tão somente o que é necessário, aos olhos da filha, que Walter saiba, agora quando já não há mais silêncios a tomarem-lhe a voz. Além disso, no momento da narração, também já não existem as imposições familiares, por isso ela consegue falar e construir o discurso que deveria ter sido comunicado a Walter em 1963:

Mas essa noite ele não precisa proteger nenhuma luz nem suster a respiração. Se o fizer será por repetição ou por memória duma clandestinidade que não se justifica. Agora Walter Dias pode deixar a porta aberta, fazer passadas de sola, ou mesmo passadas de ferro, se fosse caso disso, que poucos se importarão com o nosso laço ou com a nossa vida. Estamos protegidos pelo esquecimento tecido pelo labor dos anos e pela própria harmonia que desceu sobre a união de Maria Ema e Custódio Dias (JORGE, 1998, p. 13-14, grifo nosso).

$\mathrm{O}$ ato narrativo é, para a filha de Walter, o único meio de elaborar sua identidade de filha, a qual encontra fontes e referentes no passado comum da família. A construção dessa identidade está inscrita em um processo memorial que culmina em um discurso: por meio da narração ela reorganiza o passado, atribuindo-lhe significados não permitidos antes. Narrar o passado ao pai, então, possibilita que ela assuma a condição de filha, identidade que somente se consolida quando construída no relato da moça. 
Em 1963, ela não conseguiu elaborar qualquer discurso, mas, diante da manta recebida como legado, ela transforma em narrativa tudo o que no passado não teve voz para contar diretamente a Walter. A distância temporal entre a noite do encontro com o pai e a noite da narração, possibilitou que a filha assumisse uma voz e por isso fosse capaz de narrar-se. A passagem do tempo também permite que ela observe o passado, o encontro de 63 e todos os episódios rememorados com outros olhos; com olhos de quem tem coragem de comunicar os laços ilegítimos e enfrentar o silêncio da clandestinidade. Nesse momento, porém, o principal obstáculo que a filha encontra é o esquecimento, outra consequência do transcurso temporal.

Retomando as considerações de Hall, destaca-se que é em razão da construção discursiva da identidade que se faz necessário recorrer à memória: é preciso revolver o passado para narrar-se, para construir uma identidade, para constituir-se como sujeito diante do outro e posicionar-se dentro do grupo. Esse, portanto, é o ponto que liga a identidade à memória e torna possível a afirmação de Candau (2011, p. 18) de que "a memória é a identidade em ação".

Dessa forma, trabalhar a relação entre memória e identidade é observar como a memória guia o processo narrativo e interfere na forma como o narrador apresenta sua história e como se posiciona diante do passado narrado. No caso da filha de Walter, a memória surge na narração como forma de resistir aos silêncios e imposições familiares, que lhe negaram o lugar de filha e lhe impuseram o lugar de sobrinha. É com a narração que ela nega a posição de sobrinha, resistindo à família, ao tempo, aos silêncios e ao esquecimento ao reivindicar o lugar de filha.

Por outro lado, a distância temporal possibilita que a narradora olhe para o passado, em alguns momentos, a partir de uma perspectiva externa, como testemunha e não como protagonista da história. Esse é o Eu do presente voltando seus olhos para o passado e observando esse tempo com os pés fincados no agora. Esse aspecto do discurso da filha de Walter pode ser percebido diante da instabilidade da voz narrativa: "Também Maria Ema receava que a sobrinha de Walter não tivesse medo" (JORGE, 1998, p. 83, grifo nosso); "Sim, é preciso que Walter saiba, esta noite, em que regressa, como a filha tinha herda- 
do o vazio da casa de Valmares" (JORGE, 1998, p. 87, grifo nosso); "Quando nos olhou, sobre a calçada, surgiu o soldado Walter. E nós encontrávamo-nos, à porta, para recebê-lo" (JORGE, 1998, p. 106, grifo nosso); “Eu, então sua sobrinha, ouvia tudo" (JORGE, 1998, p. 114, grifo nosso).

Em algumas circunstâncias, a filha de Maria Ema se posiciona como narradora onisciente, testemunhando o passado da família Dias e participando de forma distante da história. Em outras situações, assume-se protagonista da trama; ora apenas relata os acontecimentos pretéritos como se não fizesse parte do universo narrativo e como se a filha de Walter e Maria Ema fosse outra pessoa. Nessas perspectivas que assume, a narradora oscila também entre nomear-se sobrinha e filha de Walter: "Mas era falso. A sobrinha de Walter sabia" (JORGE, 1998, p. 115, grifo nosso); "Quanto à filha de Walter, ela apenas tinha sido herdeira duma narrativa de amor de que conhecia os prolegómenos, o auge e o fim" (JORGE, 1998, p. 160, grifo nosso).

A distância temporal entre o momento da narração e o passado rememorado possibilita, portanto, que o sujeito da rememoração se posicione como um terceiro a observar o passado e por isso consiga mobilizar memórias de outras personagens para construir seu discurso. É nessa perspectiva que se situa a filha de Walter em alguns momentos. Quer-se alheia à história, mas atenta às personagens e aos seus pensamentos e sentimentos. Narra como se soubesse o que pensam os habitantes de Valmares; como se tivesse presenciado episódios anteriores ao seu nascimento: a cena da rebeldia de Walter aos doze anos, a notícia da gravidez de Maria Ema, a chegada de Maria Ema a Valmares, os pensamentos e comportamentos de Maria Ema diante de Walter. No entanto, por não conseguir manter esse distanciamento, a narradora varia sua perspectiva de observação do passado.

A instabilidade da voz narrativa reflete a instabilidade identitária da narradora: sempre entre a posição de sobrinha - imposta pela família - e a posição de filha - cultivada e reivindicada em silêncio até o momento da narração. No entremeio dessas posições ela anuncia-se como $\mathrm{Eu}$; um Eu que está em fase de consolidação; um Eu que ainda não encontrou seu espaço e por isso não se mostra livremente. A aparição discursiva desse $\mathrm{Eu}$ soa, inicialmente, como um acidente preparado, 
pois aos poucos ela abandona essa alternância e assume sua posição identitária de narradora da trama e filha de Walter.

Desta maneira, o processo de narração da história dos Dias é também o processo de construção da identidade de filha de Walter Dias. São eventos simultâneos: textualizar o passado e construir uma identidade. Ao longo do percurso narrativo, a posição instável da narradora vai se tornando mais firme até ela revelar-se narradora e protagonista da trama, quando toma posse do lugar de filha de Walter. Então, já no seu espaço de filha, ela não oscila mais: "A filha de Maria Ema e de Walter, isto é, a antiga sobrinha de Walter [...]" (p. 159, grifo nosso), "Lembro-me da leitura dessa carta" (p. 182, grifo nosso).

Em qualquer das perspectivas assumidas, entretanto, o discurso trai a necessidade de comunicar o que não foi possível comunicar no passado, sendo esse o ponto principal para suprir as falhas que impediram a edificação da identidade de filha de Walter Dias:

E aí ela ficou tão surpreendida que não podia falar nem pensar fosse o que fosse, presa que estava de perplexidade. Parecia-lhe impossível que Walter Dias, vindo de tão longe tivesse entrado no seu quarto, de sapatos na mão como um assaltante, e fosse afinal para lhe pedir desculpa por um facto que ela guardava para si como uma dádiva (JORGE, 1998, p. 15, grifo nosso).

A narradora apresenta a Walter - presença imaginada e imaginária evocada constantemente - a história da família; mostra que sabe do passado que também lhe pertence, ainda que clandestinamente. A filha mostra que sabe desde sempre da história de Maria Ema e de Walter: "Para quê gastar aquele tempo, estando Walter ali tão próximo, para dizer, por exemplo, que desde sempre soubera que Maria Ema havia sido mulher de dois homens, e que Francisco Dias era seu avô duas vezes?" (JORGE, 1998, p. 20).

Ela demonstra que o passado de Walter, de Maria Ema e de todos os Dias faz parte dela como filha e por meio de seu discurso insere-se nesse passado, enraizando aí sua identidade e desvelando os reais laços que a unem aos Dias e a tornam uma Dias. Ela precisa dar forma ao passado para encontrar o ponto que a une a Walter e do qual ela se origina 
na genealogia familiar. Depois de textualizar esse tempo, é importante mostrar isso a Walter e à família, encerrando o processo de construção de sua identidade de filha. É, também, por meio da narrativa, que ela revela à família a identidade construída.

É porque as identidades são construídas dentro do discurso que a narração do Eu é o instrumento para a consolidação de uma identidade (HALL, 2011). A jovem precisa, por isso, narrar tudo o que a constituiu e a constitui como filha, dirigindo-se ao pai para dizer-lhe como certos eventos se incorporaram ao seu ser. O discurso, então, reúne fragmentos do passado, unindo-os, e, a partir disso, é edificada a identidade negada:

Espere - Queria ela dizer. Durante os anos que se seguiram, eles tinham permitido que o tempo fosse desbotando, usando, transformando todos esses objetos em pedaços de coisas espalhadas pelo solo, assimiladas a ele, da mesma cor e substância. Mas ela queria dizer que havia objetos que não desapareciam, que apenas deixavam de ser matéria e de ter peso para passarem a ser lembrança. Passavam a ser fluido imaterial, a entrar e sair do corpo imaterial da pessoa, a incorporar-se na circulação do sangue e nas cavernas da memória, para aí ficarem alojados no fundo da vida, persistindo ao lado dela, e naquela noite, bastaria aproximar o candeeiro a petróleo do corpo da filha, em camisa, e agasalhada pela colcha, para confirmar como esses objetos se encontravam, morando dentro da sua cabeça. Em silêncio, sem palavras disponíveis para o dizer, ela tinha arrecadado os objetos que haviam sido a sua herança. [...] E era isso que ela quereria dizer-Ihe. Ela deveria ter dito a Walter, [...] (JORGE, 1998, p. 39-40, grifo nosso).

As lembranças passam a fazer parte do sujeito. Juntam-se para constituir o próprio sujeito, porém é necessário o relato para essa construção se efetivar. Enquanto ela não narrar sua identidade de filha não será possível assumir-se filha. Antes disso, entretanto, foi necessário reunir os elementos a partir dos quais essa identidade seria finalmente formada. Tais elementos são os argumentos e recursos memoriais que ela agencia em seu discurso, os quais se somam para formar a identidade que se consolida com a narração. A esse respeito, é importante observar que o fato de a moça proteger contra o esquecimento alguns elementos que garantiam o seu lugar de filha, mostra que ela reivindi- 
cou em silêncio essa identidade. Trata-se de uma identidade construída vagarosamente até a narração, ato final dessa construção.

De outro lado, há o silêncio familiar a impedir a edificação da identidade de filha de Walter. O silêncio é o fator que imobiliza a filha, tira-lhe a voz e furta-lhe a identidade: tudo o que é silenciado é banido do plano discursivo e entregue ao esquecimento, que se encarrega de apagar definitivamente. O silêncio impede o exercício mnemônico, limita as lembranças e manipula as imagens do passado: nega acesso aos referentes identitários. Em razão do silêncio, ela não consegue elaborar nenhum discurso, não consegue narrar-se, porque o silêncio excluiu da narrativa familiar a sua identidade de filha de Walter Dias e incluiu, coercitivamente, a identidade de filha de Custódio Dias.

Esse silêncio limitou a existência da filha de Walter diante da família, restringiu o espaço que lhe cabia no grupo e, com isso, delimitou uma identidade falsa que ela renegou, também em silêncio. Assim, a forma de resistir às censuras familiares foi o silêncio, rompido somente na noite da narração. Silenciar-se foi a maneira encontrada para se opor à família, para construir escondida em seu quarto a identidade de filha de Walter. Essa estratégia permitiu que ela suportasse por tanto tempo as imposições familiares:

Por isso, dentro do carro eu nunca tinha falado, só gritado, nunca uma única vez eu o tinha interpelado diretamente, nunca me tinha dirigido a ninguém, nem aos meus irmãos. Batíamo-nos e socavamo-nos, eles mesmos insultavam-se entre si, mas eu nunca os chamava como se ali não estivesse. Mesmo nas horas de volúpia da corrida, eu tinha feito o supremo esforço de não estar nem ausente nem presente, para que eles não sentissem o peso de minha existência, para não agravar a minha culpa (JORGE, 1998, p. 137, grifo nosso).

A postura silenciosa adotada pela narradora possibilitou que reunisse a vasta e preciosa herança de Walter (o álbum de desenhos, a foto, o revólver, a farda completa, as narrativas, a imagem). Por muito tempo, ela manteve-se obediente ao silêncio dos Dias e diante deles não conseguia falar, não tinha presença discursiva e por isso não conseguiu falar com Walter na noite de 1963. 
Outro fator a impedir que a filha de Walter fale é o pacto de silêncio feito com Maria Ema, quando a mãe solicita a presença da filha por meio do silêncio: "contribuir principalmente com a minha discrição, com meu silêncio, [...] Sim, desde essa data que estava selado entre nós o pacto do silêncio e da colaboração" (p. 138). O silêncio, que une mãe e filha, marca a relação entre elas. Não há afetividade; há silêncios.

Até a morte de Walter, à filha é concedida a licença de participar da família com o seu silêncio, de ser uma Dias silenciosa, invisível. Com a morte do pai, as censuras familiares fenecem e só então ela pode falar. Até esse momento, a filha de Maria Ema viveu em Valmares clandestina, quase como uma exilada; exilada de sua identidade, exilada de si. Ninguém a via, ninguém se importava com ela, ninguém notava a sua presença. O silêncio era a marca de sua existência: "a filha de Walter ficaria a dormir, sentindo que a vida laboriosa continuava rente ao chão, sem ninguém subir, ninguém se importar, num maravilhoso abandono total. Sem ninguém se lembrar da filha de Walter" (JORGE, 1998, p. 49-50, grifo nosso); "Naturalmente que Francisco Dias não falava para ela. Talvez ela nem ouvisse. Quase muda, não falava, não ouvia, não sabia, era indiferente que ouvisse ou não, a sobrinha de Walter" (JORGE, 1998, p. 69, grifo nosso).

Por um longo período ela manteve o silêncio como postura diante da família; ficava confortável em seu silêncio e assim convivia com o silêncio dos demais. A noite de 1963 foi a primeira ocasião em que ela quis romper o silêncio, mas não teve sucesso; o silêncio já estava entranhado nela, já fazia parte dela: "Mas aí ela quis dizer - Espere! E não conseguia dizer. Talvez por achar simples, fácil e enumerável, ela queria dizer como crescera até os quinze anos acompanhada pelo seu equipamento militar. Porque aí ele compreenderia" (JORGE, 1998, p. 37, grifo nosso).

O silêncio era a armadura que ela vestia para resistir. Escondia-se em seu silêncio e se agarrava aos objetos do pai, resguardados cuidadosamente do esquecimento na esperança de impedir o apagamento da sua condição de filha. Era preciso contar isso a Walter; narrar a sua resistência, porque esse foi o percurso para a construção de sua identidade: "Sim, eu sou apenas uma sobrinha, não me importo de o ser. Podia até 
ser menos, ser só a primeira parte do nome, ou a última, ou apenas uma sílaba, desde que por ela me fosse consentido viajar dentro do carro do meu pai a quem chamava tio (JORGE, 1998, p. 120, grifo nosso).

Em seu íntimo ela extravasava o silêncio. Em seu íntimo tudo é muito claro e definido: é filha de Walter e não de Custódio. Os laços são consolidados na clandestinidade do silêncio, mas a identidade precisa ganhar forma para que esses laços sejam, de fato, reconhecidos pela família.

Assim, o momento da narração é a ocasião de libertar-se do silêncio. É a primeira vez que ela consegue falar, dar forma aos silêncios que acompanharam sua trajetória e revelar o quanto foram significativos. Os silêncios familiares permitiram que ela reunisse os legados de Walter e montasse a sua própria herança; permitiram que ela lesse o passado do seu jeito e atribuísse os significados desejados: enxerga como herança tudo o que se relaciona com Walter e não ouve os maldizeres dos Dias a respeito de Walter, ignorando a alcunha de trotamundos, "porque sempre havia transformado o que escutava" (JORGE, 1998, p. 19).

Ela quer comunicar ao pai sobre si, sobre a vida que levou e como levou, pois ele precisa saber como ela se apropriou, em silêncio, do lugar de filha e que somente nessa noite pôde assumi-lo: "Conto-o apenas para que Walter saiba" (JORGE, 1998, p. 165). Ser filha de Walter Dias é uma condição que está determinada no passado, e não uma escolha. Por isso, é necessário revisitar esse tempo para que ela possa empossar-se do seu espaço de filha, condição que Francisco Dias deseja de todo modo impedir que se torne pública:

Francisco Dias ignorava que não podiam retirá-la, mesmo que a retirassem, ignoraria até ao último dia de sua vida. Pertencia ao grupo dos que desconhecem que existe um intervalo entre o acto e o ser, um espaço indomável que ninguém alcança e que transforma cada homem na matéria humana (JORGE, 1998, p. 82, grifo nosso).

A filha de Maria Ema esperou por Walter até o momento da narração, quando ele se fez presente por meio de sua manta. Esperou tanto tempo para contar a Walter sobre si; esperou para ocupar o papel de filha: "Havia faltado a Maria Ema a capacidade de espera, a coerência, a dureza e a fixidez necessárias para esperar por Walter, como 
sucedera com a sobrinha. [...] ela esperava pelo outro, ao contrário de Maria Ema que não tinha esperado" (JORGE, 1998, p. 88). O silêncio e a espera moldaram-na; a paciência foi o elemento principal para formar a identidade de filha: "Somos nós, os sobrinhos indistintos de Walter Dias que gritamos. A própria filha, durante esse tempo, não se importa de ser sobrinha, e grita de alegria dentro da grande barca preta conduzida pelo tio Walter que é seu pai” (JORGE, 1998, p. 120, grifo nosso).

Além dos aspectos já salientados referentes ao posicionamento discursivo da narradora, outro fator importante é a ausência de um nome, ou melhor, de um prenome. A jovem identifica-se como filha ou sobrinha de Walter, pondo-se sempre em relação a ele, atrelando sua existência a dele.

A nomeação de algo concretiza a sua existência, identifica, diferencia por estabelecer limites, definindo o que é cada coisa. O nome é marca identitária pessoal; é a primeira forma de distinção. Conforme Hall (2011), as identidades são produzidas por meio da delimitação das diferenças. Como a narradora não estabelece diferenciação em relação a Walter, sua identidade não é formada. A ausência de um nome mostra-se como uma das consequências do silêncio familiar, traduz a ausência de uma identidade e reforça as ambiguidades vivenciadas na família:

Sabia que os seus irmãos também eram seus primos, que o mesmo sangue que os unia os separava. E tinha conhecimento de que em todos os documentos de identificação havia uma mentira, mas ela colaborava com a mentira, porque da ambigüidade surgiam acontecimentos férteis e calorosos como se nascessem de verdades. [...] Lembrava-se de momentos bons e inesqueciveis, relacionados ao encobrimento e a mentira (JORGE, 1998, p. 20, grifo nosso).

$\mathrm{Na}$ verdade, ela sabe seu nome, sabe que é uma Baptista Dias, sabe de qual família provém. Seu prenome, no entanto, não é revelado e, com isso, ela não se diferencia dos demais Dias, dos demais Baptista Dias; não estabelece qualquer forma de diferenciação em relação aos seus irmãos e se mistura ao grupo familiar sem ser individualizada. Para que as diferenças sejam delimitadas, o primeiro passo é assumir como 
ela se torna uma Dias - a partir de Walter e não de Custódio. O que a faz ser uma Dias única, diferente dos demais, é o que estrutura a sua identidade: a sua ascendência.

A escrita e a narração foram o percurso para o autoconhecimento; os instrumentos indispensáveis para talhar sua identidade calcada num passado silenciado. Escrever e narrar foram os recursos utilizados para reivindicar o lugar de filha. O discurso da filha de Walter preenche as faltas, as ausências vividas pela narradora e desfaz as ambiguidades identitárias. É por meio da escrita que ela elabora sua identidade:

Mas é falso que alguma vez eu mesma tenha dito ou escrito que a filha era um resultado. [...] Falar de resultado, nesse caso, seria o embelezamento de uma ideia de vítima, e a filha de Walter era ela mesma, e a herança consistia na mistura do que herdava com a transformação da herança, feita por sua vontade. A filha de Walter ela própria gostaria de ter sido a imitação do anjo rebelado [...]. Não era, não podia ser essa imitação, mas também não pertencia a ninguém, era fruto da sua própria pessoa, ela mesma se havia parido e criado (JORGE, 1998, p. 161-162, grifo nosso).

A escrita é responsável pela identidade finalmente construída, por isso ela se percebe como fruto de sua própria pessoa: "ela mesma se havia parido e criado" a partir da escrita e da narração. Foi, no entanto, uma criação lenta e silenciosa que a passagem do tempo viabilizou.

O tempo diluiu as imposições familiares e enfraqueceu o poder de Francisco Dias, que na velhice já não pode mais determinar a ordem familiar e subjugar seus dependentes, pois já não há dependentes: agora ele é dependente do filho mais velho. A passagem do tempo também trouxe a morte de Walter, episódio que põe um fim ao drama identitário da narradora, pois, assumida ou não a filiação, já não há mais pai para ocupar o posto. Esse é o clima em que a filha de Maria Ema constrói sua narrativa memorial.

O fluxo temporal enfraqueceu os obstáculos que impediam o discurso, mas também trouxe a emergência memorial, a ameaça do esquecimento definitivo. Narrar, então, tornou-se um imperativo, pois o tempo e a morte do pai levariam para o esquecimento todos os vestígios de um passado já borrado e distorcido pela família. Por isso, esse passado precisava ser fixado, capturado no momento exato em que as 
lembranças enfraquecem até apagarem-se. Neste momento, então, o discurso é o único instrumento capaz de cristalizar o tempo pretérito:

A necessidade de escrever a história de um período, de uma sociedade e até mesmo de uma pessoa só desperta quando elas já estão bastante distantes no passado para que ainda se tenha por muito tempo a chance de encontrar em volta diversas testemunhas que conservam alguma lembrança. Quando a memória de uma sequência de acontecimentos não tem mais por suporte um grupo, [...], então o único meio de preservar essas lembranças é fixá-las por escrito em uma narrativa, pois os escritos permanecem, enquanto as palavras e o pensamento morrerem (HALBWACHS, 2006, p. 101).

A filha precisa fixar suas memórias porque sua identidade está ancorada num passado clandestino; precisa capturar esse tempo para não deixá-lo fenecer juntamente com Walter: "Então é preciso lembrar mais, esta noite, para que Walter saiba, antes de nos despedirmos" (JORGE, 1998, p. 206). É a escrita e a narração que permitem a captura do passado, pois a rememoração se operacionaliza convertendo as lembranças em presença discursiva (SARLO, 2007, p. 99).

Dessa forma, o discurso finalmente construído permite que ela abandone a clandestinidade que marcara sua existência em Valmares e assuma o lugar de filha de Walter perante à família e ao pai. Assim, o ato narrativo é o único meio que ela dispõe para falar; por isso ela recupera, por intermédio do discurso, tudo o que queria ter feito e ter dito, tudo o que poderia ter acontecido e narra isso para que Walter saiba. Com o seu discurso, portanto, ela dá forma a toda clandestinidade e silêncios de sua vida para que Walter saiba e para, com isso, romper o esquecimento, para ser e se tornar o que nunca pode ser e assumir.

\section{CONSIDERAÇÕES FINAIS}

A ideia de identidade que norteia esta leitura é de um processo que se inicia com o nascimento e acompanha o sujeito até o fim da vida, de modo que as identidades são abertas: estão em permanente processo de constituição. Nesse sentido, identidade é uma posição social que o sujeito assume, por isso é compreendida como um processo. Leva-se 
em conta, também, que as posições sociais são elaboradas discursivamente, são narradas, e, assim, a identidade é compreendida como uma construção discursiva.

De outra parte, a memória é abordada como a faculdade que permite ao indivíduo acessar o próprio passado, tornando-o consciente do tempo e do seu fluxo. Com isso, a memória permite também que o indivíduo atribua significados às experiências vividas. É a memória, portanto, que interliga os tempos: presente e passado com vistas ao futuro, servindo como instrumento para o autoconhecimento. Permeada por lembranças e esquecimentos, no entanto, o passado é revisitado obedecendo às intenções do sujeito da rememoração, as quais revelam a posição identitária almejada. A memória, então, é percebida como um dos pilares em que se funda a identidade. É a fonte de referentes e o instrumento que permite a ressignificação do passado que ancorará uma nova posição social a ser assumida pelo sujeito.

Com o olhar voltado para este horizonte teórico, o romance de Jorge foi lido tendo em vista a atuação da memória na construção e reconstrução da identidade individual da narradora. A manipulação das memórias, a seletividade e o enquadramento feito pela narradora em relação ao passado foram discutidos observando-se em que medida a memória participa do processo de reelaboração identitária e a forma como a narração se forjou como ato de resistência.

A filha de Walter Dias apresenta uma narrativa elaborada a partir das lembranças de sua infância; uma retrospectiva pessoal que mobiliza toda a família e agencia discursos esparsos que a narradora-protagonista costura para montar o passado familiar e se inserir nesse passado a partir de outra postura: a de filha.

Neste contexto, a narração se mostra como um percurso para o autoconhecimento, para formar uma identidade silenciada por anos de dissimulações familiares. É narrando, portanto, que a filha de Walter desfaz os esquecimentos e silêncios que formam a história dos Dias. É narrando que ela resiste ao esquecimento e ao silêncio.

$\mathrm{O}$ esquecimento, o silêncio e a morte são os instigadores do exercício mnemônico, provocadores do trabalho memorial e do labor do discurso empreendido para reconstruir um tempo ao qual se tem acesso aos pedaços. É tecendo esse discurso que a narradora afirma e 
firma suas ligações com a família a partir de uma posição diferente. Esse é o desenlace alcançado pela filha de Maria Ema e de Walter Dias.

NARRATION AS AN ACT OF RESISTANCE IN “THE PAINTER OF BIRDS”, By LíDIA JORGE

\begin{abstract}
We present a novel reading of "The Painter of Birds" by Lídia Jorge, in which it is highlighted the role of the narrative as an act of resistance to forgetfulness and family silence. It is a narrative that mobilizes memories to consolidate an identity from the reframing of the past. For that, the identity is approached as an eminently discursive process attached to the memory, as it finds in the past one of its main constitutive sources. The means to appease the conflicts of the past are writing, narrating, because it is the anguish of knowing her identity as a daughter and the impossibility of bearing it that drives the protagonist narrator to revolve the past. Narrating a clandestine past, from which she was banned trough the familiar discourse, it is forged as an act of resistance.
\end{abstract}

Keywords: Narration, identity, memory, The Painter of Birds.

Narración como acto de Resistencia en $O$ VALE DA PaIXão, de Lídia JORGE

\title{
RESUMEN
}

Presentamos una lectura de la novela $O$ Vale da Paixão, de Lídia Jorge, que destaca el papel de la narración como forma de resistencia a los olvidos y silencios familiares. Se trata de una narración que moviliza recuerdos para consolidar una identidad desde de la resignificación del pasado. La identidad se aborda aquí como un proceso eminentemente discursivo acoplado a la memoria, una vez que encuentra en el pasado una de las principales fuentes constituidoras. En esta narrativa, el camino para apaciguar los conflictos del pasado es la escrita, la narración. Narrar un pasado clandestino, que fue prohibido por medio del discurso familiar, se forja como un acto de resistencia.

Palabras-Clave: narración, identidad, memoria, O Vale da Paixão. 
NotA

1 Doravante, as citações do romance em análise serão acompanhadas apenas da indicação da página.

\section{REFERÊNCIAS}

CANDAU, Joël. Memória e identidade. São Paulo: Contexto, 2011.

HALBWACHS, Maurice. A memória coletiva. São Paulo: Centauro, 2006.

HALL, Stuart. A identidade cultural na pós-modernidade. Rio de Janeiro: DP\&A, 2006.

HALL, Stuart. Quem precisa de identidade? In: SILVA, Tomaz Tadeu da (Org.). Identidade e diferença. Petrópolis: Vozes, 2011.

JORGE, Lídia. O vale da paixão. Lisboa: Publicações Dom Quixote, 1998.

SARLO, Beatriz. Tempo passado: cultura da memória e guinada subjetiva. São Paulo: Companhia das Letras, 2007.

Submetido em 08 de janeiro de 2015.

Aceito em 04 de agosto de 2015.

Publicado em 21 de agosto de 2015 